\title{
A practical means of evaluating the prognosis of acute pancreatitis, as measurement of carotid artery intima-media thickness
}

\author{
K. Kurkcu', B. Kara ${ }^{2}$, A. S. Koc ${ }^{3}$ S. O. Keskek
}

(1) Department of Internal Medicine, University of Health Sciences, Adana City Research and Education Hospital, Adana Turkey ; (2) Department of Internal Medicine, Division of Gastroenterology, University of Health Sciences, Adana City Research and Education Hospital, Adana, Turkey ; (3) Department of Radiology, University of Health Sciences, Adana City Research and Education Hospital, Adana, Turkey ; (4) Department of Internal Medicine, Alaaddin Keykubat University, Alanya, Turkey.

\begin{abstract}
Backgroung and study aims: Factors such as age, obesity, diabetes mellitus and hyperlipidemia that cause adverse prognosis in acute pancreatitis also cause an increase in carotid intima-media thickness. In this study, we aimed to investigate the usability of the measurement of carotid intima-media thickness, which is an easy to apply, cost-effective means of measurement applied to the patients, in predicting AP prognosis, apart from the criteria currently utilized to predict AP prognosis.

Patient and methods: 101 patients diagnosed with acute pancreatitis were prospectively enrolled into the study. Right and left common carotid artery intima-media thickness, right and left internal carotid artery intima-media thickness were measured with ultrasonographic images performed within the first 24 hours of hospitalization. local or systemic complications and organ failure development were monitored in the follow-up of the patients.

Results: After the ROC analysis was performed and the threshold value was determined. The patients with main and internal carotid artery intima-media thickness above $0.775 \mathrm{~mm}$ were seen to have a more severe $\mathrm{AP}(\mathrm{p}=\mathbf{0 . 0 0 0})$. Local and systemic complications and organ failure were also more common in these patients.
\end{abstract}

Conclusions: Measurement of carotid intima-media thickness is a non-invasive method that can be used to predict the prognosis in patients with acute pancreatitis at presentation. (Acta gastroenterol. belg., 2021, 84, 437-442).

Key words: Acute pancreatitis, severity, carotid intima-media thickness

\section{Introduction}

Acute pancreatitis (AP) is a disease characterized by inflammation of the pancreas due to the activation of pancreatic enzymes. The incidence of the disease is considered to be 13-45 / 100,000; however, the incidence rate increases over time (1). While the disease may have a good prognosis if affecting only the pancreas, it can also result in multiple organ failure and mortality. Mortality rates have been determined as 3\% in mildly edematous form, while $15 \%$ in acute necrotizing form (2). Therefore, early diagnosis of necrosis is very important in determining the severity and prognosis of the disease.

Age, obesity, alcohol, diabetes mellitus and hyperlipidemia, listed among the risk factors in acute pancreatitis severity, are also risk factors in the etiology of atherosclerosis (3). Atherosclerosis is a multifactorial, chronic inflammatory disease characterized by impaired blood flow to organs and limbs as a result of narrowing of the lumen (4). It occurs in the intima and media layers of the arterial wall and emerges mainly in response to endogenously modified structures, particularly oxidized lipoproteins, which stimulate both innate and adaptive immune responses (5). Studies have shown that increased intima-media thickness is an important indicator of atherosclerosis, which plays an important role in the development of cerebrovascular and cardiovascular disease (6). Carotid arteries are the most widely used vessels in the measurement of intima-media thickness (IMT) due to their size, easy visibility, superficiality and immobility (7-9). The mean value of intima-media thickness in the population ranges between $0.4-1 \mathrm{~mm}$ and an annual increase of $0.01-0.03 \mathrm{~mm}$ is observed. It has been reported that increased carotid intima-media thickness (CIMT) values are also associated with increased risk of heart attack and stroke in elderly and middle-aged adults without a previous history of cardiovascular disease (10). Various scoring systems and predictive parameters, including clinical, laboratory and radiological criteria, have been defined for the early diagnosis of severe AP. In our study, we aimed to investigate the usability of CIMT measurement in early evaluation of patients in order to get preliminary information about AP prognosis.

\section{Material and method}

This study was carried out prospectively and observationally in Adana City Training and Research Hospital. The ethics committee approval was obtained on 14.09.2018. (Decision no : 272) Following this date, the patients who were hospitalized in Internal Medicine, Gastroenterology and Internal Medicine Intensive Care clinics who were diagnosed with acute pancreatitis over the age of 18 were included in the study. Informed consents were obtained from the patients enrolled in the study, after they were informed about the study. Patients who did not consent to participate in the study, those with chronic pancreatitis, the pregnant ones, and those with any malignancy were excluded from the study. The patients included in the study were evaluated at three

Correspondence to : Banu Kara, AP., Department of Gastroenterology, University of Health Sciences- Adana City Research and Education Hospital, Adana Şehir Hastanesi, Dr. Mithat Ozsan Bulvarı, Kışla mah. 4522 sok. No : 1 Yüreğir, Adana, Turkey. Phone : +(90) 5056177309.

E-mail: banu.banu97@gmail.com

Submission date : 29/04/2020

Acceptance date : 02/01/2021 
Table 1. - Marshall scoring system

\begin{tabular}{|c|c|c|c|c|c|}
\hline \multirow{2}{*}{ Organ Systems } & \multicolumn{5}{|c|}{ Score } \\
\hline & $\mathbf{0}$ & 1 & 2 & 3 & 4 \\
\hline Respiratory (PaO2/FiO2) & $>400$ & $301-400$ & $201-300$ & $101-200$ & $\leq 101$ \\
\hline Renal (serum creatinine $\mathrm{mg} / \mathrm{dl}$ ) & $<1,4$ & $1,4-1,8$ & $1,8-3,2$ & $3,2-4,5$ & $>4,5$ \\
\hline Cardiovascular (systolic blood pressure $\mathrm{mmHg}$ ) & $>90$ & $\begin{array}{l}<90 \\
\text { Response to fluid replacement }\end{array}$ & $\begin{array}{l}<<0 \\
\text { No response to fluid replacement }\end{array}$ & $\begin{array}{c}<90 \\
\mathrm{Ph}<7,3\end{array}$ & $\begin{array}{c}<90 \\
\mathrm{Ph}<7,2\end{array}$ \\
\hline
\end{tabular}

$\mathrm{PaO} 2$ / FiO2 : Partial oxygen pressure / Oxygen ratio in exhaled air.

monthly follow-up controls for a period of six months. They were followed up in terms of the development of complications. The demographic characteristics of the patients, the local and systemic complications, organ failure status, and accompanying diseases were recorded in the data form. They were followed up for the development of complications. The disease severity was divided into three according to the modified Atlanta Criteria used in the classification of acute pancreatitis (11). The patients were classified as mild AP (There are no organ failure and local or systemic complications), moderate AP (There are transient organ failure that resolves within 48 hours and / or local or systemic complications without permanent organ failure.) and severe AP (There is permanent organ failure in one or more organs.) according to the Modified Atlanta Criteria. Respiratory, cardiovascular and kidney functions are evaluated to define organ failure. Organ failure is defined as an obtained score of 2 or more for one of these three organ systems using the modified Marshall scoring system (11). (Table 1) When it comes to local complications, they were defined as acute peripancreatic fluid collection (extrapancreatic fluid associated with interstitial edematous pancreatitis, seen in the first 4 weeks), acute necrotic collection (collection containing necrotizing pancreatitis-associated fluid and necrosis, seen within the first 4 weeks.), pancreatic pseudocyst (encapsulated fluid collection without necrosis after pancreatitis with interstitial edema) and organized necrosis (encapsulated collection in necrotizing pancreatitis, seen after 4 weeks) (12). Systemic complications in acute pancreatitis occur more frequently in severe cases and necrotizing pancreatitis attacks. Systemic complications can be classified as pulmonary complications, cardiovascular system complications, renal disorders, coagulation disorders, hypocalcemia, hyperglycemia, hyperlipidemia, encephalopathy (12).

When power analysis was performed for the research, the sample size was calculated as 102 patients for the alpha significance level of $0.05,95 \%$ power, assuming that the mean effect size (effect size: 0.4 ) would be accepted as a difference in the mean of the parameters in which the carotid intima-media thickness was examined. However, since our study was conducted prospectively and informed consent was obtained, a total of 101 patients could be included in the study. During the course of the study, 273 patients with acute pancreatitis were observed, but the intended number of patients could not be reached as 57 patients who presented with mild pancreatitis, 26 patients with moderate pancreatitis and 18 patients who presented with severe pancreatitis agreed to participate in the study.

CIMT was evaluated by an experienced unblind radiologist within 24 hours of hospitalization. The patients were screened in the supine position. The participants were made sure to turn their heads 45 degrees from the direction of the screened carotid artery. CIMT was measured over two-dimensional ultrasound images from the distant walls of the right or left carotid artery 10 $\mathrm{mm}$ before (main carotid) or later (internal carotid) parts of the bifurcation. The right and left common carotid arteries were screened with a high resolution ultrasound Doppler system (Philips EPIQ 7) equipped with an 8-12 Mhz high resolution linear transducer (Philips Health Care, Bothell, WA, USA). All arteries were examined in both longitudinal and transverse axes. All arteries were examined longitudinally in order to view the CIMT on the posterior or distal wall of the artery. All measurements were made over frozen images. Two images of the best quality were selected for analysis of each participant. CIMT was determined as the distance from the anterior line of the first echogenic line to the anterior edge of the second line. The first line indicates the intima-lumen interface, and the second line indicates the upper layer of adventitia containing collagen. Vascular CIMT was measured by an independent and blinded observer using ultrasonic calipers. All CIMT values were taken as the average of six measurements.

\section{Statistical Analysis}

We used SPSS 23.0 package program for the statistical analysis of the data. Categorical measurements were summarized as numbers and percentages, while the continuous measurements were categorized as mean, deviation, and minimum-maximum. The conformity of the variables to normal distribution was examined using visual (histogram and probability graphs) and analytical methods (Kolmogorov-Smirnov / Shapiro-Wilk Tests). Chi-square test and Fischer's Precision Test were used in the comparisons of categorical variables. One-way ANOVA was used for parameters conforming to normal distribution and Kruskal Wallis tests were used for those which did not. The sensitivity (sensitivity) and specificity (specificity) values of the right and left main carotid artery (CCA) and internal carotid artery (ICA) findings of the patients included in the study were calculated based on the revised Atlanta variable, also the cut-off value was 
determined by examining the area under the ROC curve. Statistical significance level was taken as 0.05 in all tests.

\section{Results}

The demographic characteristics and clinical findings of all patients are summarized in Table 2. The mean, standard deviation, minimum and maximum age values, right CCAIMT, left CCAIMT, right ICAIMT, left ICAIMT, laboratory test values were examined for each group (Table 3). The differences between the etiological distribution and gender of the patients and the revised Atlanta score groups were not found to be statistically significant $(\mathrm{p}>0.05)$. We could not find evidence of etiology in 16 patients identified as idiopathic. The differences between the values of HB, AST, ALT, Creatinine, Glucose, CRP and LDH and the revised Atlanta score findings of the patients were not statistically significant $(\mathrm{p}>0.05)$. The patients classified as moderate and severe according to revised Atlanta score were of older ages $(p<0.05)$. The incidence of local complications was found to be statistically significantly higher in patients classified as moderate and severe based on their revised Atlanta scores compared

\section{Table 2. - Demographic and clinical features of patients}

\begin{tabular}{|c|c|c|c|}
\hline \multicolumn{2}{|l|}{ Measurements } & \multirow{2}{*}{$\begin{array}{c}\text { Number of } \\
\text { Patients(n) }\end{array}$} & \multirow{2}{*}{$\begin{array}{c}\begin{array}{c}\text { Percent } \\
(\%)\end{array} \\
70,3 \\
\end{array}$} \\
\hline Local & No & & \\
\hline Complications & Peripancreatic collection & 27 & 26,7 \\
\hline & Pseudocyst & 2 & 2,0 \\
\hline & Acute necrotic collection & 1 & 1,0 \\
\hline \multirow{2}{*}{$\begin{array}{l}\text { Systemic } \\
\text { Complications }\end{array}$} & No & 74 & 73,3 \\
\hline & Yes & 27 & 26,7 \\
\hline \multirow[t]{6}{*}{ Co-morbidity } & No & 57 & 56,4 \\
\hline & $\mathrm{HT}^{\mathrm{t}}$ & 30 & 30,0 \\
\hline & $\mathrm{DM}^{\#}$ & 17 & 16,9 \\
\hline & Coroner artery disease & 15 & 14,9 \\
\hline & $\mathrm{COPD}^{\mathfrak{k}} /$ Astma & 19 & 18,9 \\
\hline & $\mathrm{RF}^{\|}$ & 7 & 6,9 \\
\hline \multirow[t]{4}{*}{ Etiologies } & Biliary & 79 & 78,2 \\
\hline & Idiopathic & 16 & 15,8 \\
\hline & Alcohol & 2 & 2,0 \\
\hline & Hypertriglyceridemia & 4 & 4,0 \\
\hline \multirow{3}{*}{$\begin{array}{l}\text { Modified } \\
\text { Atlanta } \\
\text { Classification }\end{array}$} & Mild & 57 & 56,4 \\
\hline & Moderately Severe & 26 & 25,7 \\
\hline & Severe & 18 & 17,8 \\
\hline \multirow[t]{4}{*}{ Organ Failure } & No & 71 & 70,3 \\
\hline & Cardiac & 16 & 15,9 \\
\hline & Respiratory & 25 & 25,0 \\
\hline & RF & 7 & 6,9 \\
\hline \multirow{3}{*}{$\begin{array}{l}\text { Duration of } \\
\text { organ failure }\end{array}$} & No organ failure & 71 & 70,3 \\
\hline & $<48$ hours & 14 & 13,9 \\
\hline & $>48$ hours & 16 & 15,8 \\
\hline \multirow[t]{2}{*}{ Sex } & Male & 42 & 41,6 \\
\hline & Female & 59 & 58,4 \\
\hline \multicolumn{2}{|l|}{ Total } & 101 & 100,0 \\
\hline
\end{tabular}

${ }^{\mathrm{E}} \mathrm{HT}$ : hypertension, ${ }^{\# D M}$ : diabetes mellitus, ${ }^{\mathrm{T}} \mathrm{RF}$ : renal failure, ${ }^{\mathrm{f}} \mathrm{COPD}$ : cronic obstructive pulmonary disease.

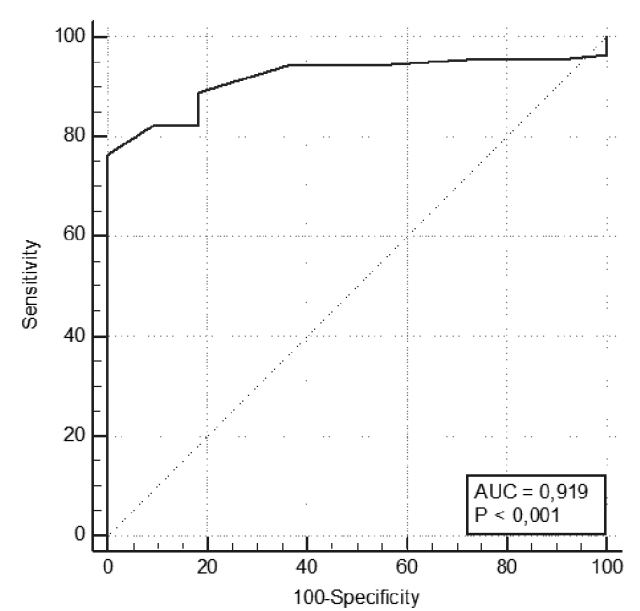

Figure 1. - Roc curve analysis of CCACIA (median) parameters according to the revised Atlanta variable.

to the patients classified as mild $(\mathrm{p}<0.05)$. The presence of a comorbid disease was statistically significant in patients with a mild revised Atlanta score than the patients in the moderate and severe group $(p<0.05)$. Another statistically significant point to dwell on was the incidence of organ failure, which was higher in patients with the revised Atlanta score of moderate and severe compared to patients with a mild revized Atlanta score $(p<0.05)$. In patients classified according to the revised Atlanta criteria, while no comorbid disease was found in any of the patients classified as mild pancreatitis, there was a comorbid disease in 17 of $26(66 \%)$ patients classified as moderate pancreatitis. All patients $(100 \%)$ with severe pancreatitis were seen to have a comorbid disease. It was determined that the left CCA $(p=0.000)$ and WBC $(p=0.003)$ values of the patients with a mild revised Atlanta score were statistically significantly lower than those classified in the other groups $(p<0.05)$. The differences between the length of hospitalization and the revised Atlanta score groups were statistically significant $(p<0.05)$. According to the Post Hoc Bonferrino analysis conducted to determine the source of the difference between the groups, it was found that the mean length of hospitalization of the patients with severe AP was significantly higher than the patients with a mild $(p=0.000)$ and moderate $(p=0.000)$ revised Atlanta scores. In addition, the mean length of hospitalization was statistically significant in patients with a moderate revised Atlanta score compared to patients with a mild score $(\mathrm{p}<0.05)$.

In order to establish a cut-off value for the main and internal carotid artery intima-media thickness (CCACIA) median value, ROC analysis was performed with revised Atlanta variable and a ROC curve was created for the CCACIA median value. As a result of the ROC analysis, the area under the ROC curve was calculated as $91.9 \%$, which means that the cut off value obtained gives the correct answer at the rate of $91.9 \%$. According to the cut off value we obtained, if the CCACIA median value is above $0.775 \mathrm{~mm}$, it contributes to the prediction of 
Table 3. - Characteristics of the groups according to the severity of pancreatitis

\begin{tabular}{|c|c|c|c|c|}
\hline & $\begin{array}{c}\text { Mild } \\
\text { (n: 72) }\end{array}$ & $\begin{array}{c}\text { Moderate } \\
\text { (n: 18) }\end{array}$ & $\begin{array}{l}\text { Severe } \\
(n: 11)\end{array}$ & p \\
\hline & Ort \pm ss & $\operatorname{Ort} \pm \mathbf{s s} \pm 17,21$ & Ort \pm ss & \\
\hline Age & $50,76 \pm 18,93$ & $60,78 \pm 17,21$ & $65,45 \pm 19,50$ & $0,016 *$ \\
\hline Right CCA (mm) & $0,65 \pm 0,20$ & $0,75 \pm 0,19$ & $1,0 \pm 0,10$ & $0,000 *$ \\
\hline Right ICA (mm) & $0,60 \pm 0,28$ & $0,69 \pm 0,27$ & $0,94 \pm 0,23$ & $0,000 *$ \\
\hline Left CCA (mm) & $0,66 \pm 0,22$ & $0,80 \pm 0,18$ & $0,99 \pm 0,12$ & $0,000 *$ \\
\hline Left İCA (mm) & $0,59 \pm 0,29$ & $0,67 \pm 0,40$ & $0,90 \pm 0,16$ & 0,001* \\
\hline $\mathrm{WBC} / \mathrm{mm} 3$ & $9685,35 \pm 4283,3$ & $12762,1 \pm 5283,5$ & $14518,1 \pm 5539,8$ & $0,003 *$ \\
\hline $\mathrm{HB} \mathrm{mg} / \mathrm{dl}$ & $13,12 \pm 1,65$ & $13,23 \pm 2,31$ & $12,07 \pm 2,01$ & 0,184 \\
\hline $\mathrm{AST} u / 1$ & $174,42 \pm 214,5$ & $210,2 \pm 292,9$ & $266,0 \pm 267,6$ & 0,645 \\
\hline ALT u/l & $175,8 \pm 210,6$ & $187,2 \pm 213,9$ & $202,1 \pm 259,4$ & 0,964 \\
\hline UREA mg / dl & $36,01 \pm 30,19$ & $50,77 \pm 35,06$ & $57,26 \pm 61,13$ & $0,006 *$ \\
\hline Creatinine mg / dl & $0,95 \pm 1,15$ & $1,17 \pm 1,25$ & $1,24 \pm 1,31$ & 0,135 \\
\hline Glucose mg / dl & $142,03 \pm 76,51$ & $161,44 \pm 80,25$ & $178,09 \pm 77,99$ & 0,083 \\
\hline CRP mg/l & $3,89 \pm 5,72$ & $4,70 \pm 5,85$ & $7,70 \pm 6,15$ & 0,064 \\
\hline $\mathrm{LDH} \mathrm{u/1}$ & $392,45 \pm 350,03$ & $676,0 \pm 1212,33$ & $436,6 \pm 257,09$ & 0,151 \\
\hline Lenght of Hospitalization & $2,92 \pm 1,25$ & $5,17 \pm 2,28$ & $9,91 \pm 6,22$ & $0,000 *$ \\
\hline CCAICA Median & $0,61 \pm 0,22$ & $0,72 \pm 0,20$ & $0,95 \pm 0,09$ & 0,000* \\
\hline Prevelance of Comorbidity & $\% 0$ & $\% 66$ & $\% 100$ & $0,000 *$ \\
\hline
\end{tabular}

* Statistical significance (p) level was taken as 0.05 in all tests.

Table 4. - Interpretation of CCACIA (median) parameters according to ROC curve analysis based on the revised atlanta variable

\begin{tabular}{|l|c|}
\hline & CCACIA Median \\
\hline AUC & 0,919 \\
\hline Cut-off & $\leq 0,775$ \\
\hline Sensitive (\%) & 76,67 \\
\hline $\mathbf{9 5 \% - C l ~ ( \% ) ~}$ & $66,6-84,9$ \\
\hline Spesitive & 100,0 \\
\hline $\mathbf{9 5 \% - C l ~ ( \% ) ~}$ & $71,5-100$ \\
\hline PPV & 100 \\
\hline NPV & 34,4 \\
\hline $\mathbf{p}$ & $<0,001$ \\
\hline
\end{tabular}

the severity of the disease with $76.67 \%$ sensitivity and $100.00 \%$ specificity (Figure-1, Table 4 ).

\section{Discussion}

Acute pancreatitis (AP) is an inflammatory disease with a variety of clinical features ranging from mild cases presenting with only transient abdominal symptoms to severe fatal ones. (2) Therefore, early recognition of necrosis is of big importance in determining the severity and prognosis of the disease. Various scoring systems have been developed to determine the severity of the disease in patients with increased morbidity and mortality which offer the chance to determine whether the patient will be treated in the intensive care unit or the ward (13).

The primary cause of early mortality in AP stems from the excessive inflammatory response and multiorgan failure. The first sign of multiple organ failure in patients with AP is lung dysfunction, usually caused by acute respiratory distress syndrome. Systemic inflammation also affects the cardiovascular system, kidneys, and liver (14). Early and permanent organ failure is reliable predictor of increased hospitalization and mortality. It has been reported that the occurrence of organ failure within 72 hours is associated with extensive pancreatic necrosis and also with a mortality rate of $42 \%$. The clinical course of organ failure is a more accurate predictor of adverse consequences. (15) The clinical decision based on clinical and laboratory data at the time of admission is insufficient to define the severity of acute pancreatitis (16). Although the Balthazar Score has been shown to be a better predictor of AP severity than Ranson or APACHE II scores, it has not yet been significantly associated with the development of organ failure (17). Recently, Raghuwanshi et al. found that the modified Atlanta classification provides more accurate assessment of patient mortality and of organ failure than the Balthazar and Mortele indices (18). The modified Atlanta classification system provides a more accurate assessment of patient mortality and organ failure than the Balthazar and Mortele indices, but cannot distinguish between moderately severe and severe AP cases within 48 hours from baseline (19). Although there are many scoring systems developed for AP severity classification, none are ideal means of prediction for mortality. Such issues as high predictive value, easy applicability and total cost to be incured to the patient and universal health insurance are of big importance even in the early stages of the disease (20). However, there is no scoring system that will fully meet these criteria. In our study, we found the intima-media thickness of both the common carotid artery and the internal carotid artery over the threshold value determined in severe and moderate AP groups and in those with local and systemic complications and in those needing more prolonged hospitalization than others. Based on these results, we can make the following conclusion: The presence of factors that increase carotid intima-media thickness also adversely 
affects the prognosis of acute pancreatitis. There are studies in the literature suggesting that carotid intimamedia thickness in the presence of atherosclerosis increases and that carotid intima-media thickness can be used as an indicator of atherosclerosis $(21,22)$. CIMT is an independent predictor of coronary events such as myocardial infarction, stroke, and transient ischemic attack (23). Atherosclerosis is a systemic and progressive disease occuring at an early age which affects the middle and large arteries (24). While atherosclerosis occurs in the intima media, the main reason for the thickening of the media layer is smooth muscle hypertrophy. Endothelial dysfunction or disruption of the intimamedia layers are early signs of atherosclerosis $(25,26)$. As is known, comorbidities such as aging, diabetes mellitus, obesity, and hyperlipidemia resulting in atherosclerosis and an increase in carotid intima-media thickness also negatively affect the prognosis of pancreatitis (27-29). In our study, comorbid DM, coronary artery disease and HT were encountered more frequently in patients presenting with more severe pancreatitis, and the severity of the disease was in parallel with the advanced age. Acute pancreatitis prognosis was worse in patients with carotid intima-media thickness above the specified thresholds than those below.

Our study had some limitations. Since the study was conducted prospectively, the consent was obtained from the patients who participated in the study, however, 162 of the patients who presented to our hospital with acute pancreatitis did not consent to participate in the study, thus making a larger sample group impossible. Diagnoses of pancreatitis caused by hypercalcemia and toxic pancreatitis, which are among the etiology of acute pancreatitis, were not available in our sample. For this reason, we cannot generalize our findings for all acute pancreatitis etiology. The fact that there is no previous study similar to our study can also be considered as a limitation, as it makes comparison impossible.

\section{Conclusion}

We demonstrated that measurement of common carotid artery intima-media thickness applied in AP patients can be used as a method to predict prognosis. Measurement of carotid artery intima-media thickness by ultrasonography is a method that has not been studied in patients with acute pancreatitis, which is a fast, inexpensive, non-invasive test that can be used to predict the prognosis of acute pancreatitis.

\section{Conflict of interest}

We declare that we have no conflict of interest.

\section{References}

1. YADAV D., ALBERT BL. The epidemiology of pancreatitis and pancreatic cancer. Gastroenterology, 2013, 144: 1252-61. doi : 10.1053/j. gastro.2013.01.068.
2. VAN SANTVOORT H.C., BAKKER O.J., BOLLEN T.L., BESSELINK M.G., AHMED A. U., SCHRIJVER A.M., et al. A conservative and minimally invasive approach to necrotizing pancreatitis improves outcome. Gastroenterology, 2011, 141 : 1254-1263. doi : 10.1053/j.gastro.2011.06.073.

3. QU B., QU T. Causes of changes in carotid intima-media thickness : a literature review. Cardiovasc. Ultrasound., 2015, 13 : 46. doi : 10.1186/ s12947-015-0041-4

4. TEDGUi A., MALlAT Z. Cytokines in atherosclerosis: Pathogenic and regulatory pathways. Physiol. Rev., 2006, 86: 515-581. doi : 10.1152/ physrev.00024.2005.

5. WEBER C., ZERNECKE A., LIBBY P. The multifaceted contributions of leukocyte subsets to atherosclerosis : lessons from mouse models. Nat. Rev. Immunol., 2008, 8 : 802-815. doi : 10.1038/nri2415.

6. RAGGI P., GENEST J., GILES J.T., RAYNER K.J., DWIVEDI G., BEANLANDS R.S., et al. Role of inflammation in the pathogenesis of atherosclerosis and therapeutic interventions. Atherosclerosis., 2018, 276 : 98-108. doi : 10.1016/j.atherosclerosis.2018.07.014.

7. KA TAKAMI N., KANETO H., SHIMOMURA I. Carotid ultrasonography : A potent tool for better clinical practice in diagnosis of atherosclerosis in diabetic patients. J. Diabetes Investig.,2014, 5 : 3-13. doi : 10.1111/jdi.12106.

8. NADEEM R., HARVEY M., SINGH M., KHAN A.A., ALBUSTANI M., BAESSLER A., et al. Patients with obstructive sleep apnea display increased carotid intima media : a meta-analysis. Int. J. Vasc. Med., 2013, 839-858. doi : 10.1177/0003319716665985.

9. TYRRELL P.N., BEYENE J., FELDMAN B.M., MCCRINDLE B.W., SILVERMAN E.D., BRADLEY T.J. Rheumatic disease and carotid intimamedia thickness : a systematic review and meta-analysis. Arterioscler. Thromb. Vasc. Biol., 2010, 30 :1014-1026. doi : 10.1161/ATVBAHA.109.198424

10. TADA H., NAKAGAWA T., OKADA H., NAKAHASHI T., MORİ M., SAKATA K., et al. Clinical Impact of Carotid Plaque Score rather than Carotid Intima-Media Thickness on Recurrence of Atherosclerotic Cardiovascular Disease Events. J. Atheroscler. Thromb., 2020, 27 : 38-46. doi : 10.5551/ jat.49551.

11. KADIYALA V. The Atlanta Classification, Revised Atlanta Classification, and Determinant-Based Classification of Acute Pancreatitis Which Is Best at Stratifying Outcomes?, Pancreas, 2016, 45(4) :510-515. doi : 10.1097/ MPA.0000000000000477

12. WINDSOR JA, JOHNSON CD. Classifying the severity of acute pancreatitis : Towards a way forward, Pancreatology 2015; 15 : 101-104. doi : 10.1016/j. pan.2015.01.006.

13. MOUNZER R., LANGMEAD C.J., WU B.U. Comparison of existing clinical scoring systems to predict persistent organ failure in patients with acute pancreatitis. Gastroenterology, 2012, $142: 1476-1482$. doi : 10.1053/j. gastro.2012.03.005

14. PAPACHRISTOU G.I., CLERMONT G., SHARMA A., YADAV D., WHITCOMB D.C. Risk and markers of severe acute pancreatitis. Gastroenterology Clinics of North America., 2007, 36 : 277-296. doi 10.1016/j. gtc.2007.03.003.

15. JOHNSON C., ABU-HILAL M. Persistent organ failure during the first week as a marker of fatal outcome in acute pancreatitis. Gut., 2004, 53 : 1340-1344. doi : 10.1136/gut.2004.039883.

16. HAGJER S., KUMAR N. Evaluation of the BISAP scoring system in prognostication of acute pancreatitis. A prospective observational study. International Journal of Surgery, 2018, 54: 76-81. doi : 10.1016/j.ijsu. 2018.04.026.

17. LEUNG T.K., LEE C.M., LIN S.Y., CHEN H.C., WANG H.J., SHEN L.K., et al. Balthazar computed tomography severity index is superior to Ranson criteria and Apache II scoring system in predicting acute pancreatitis outcome. World J. Gastroenterol., 2005, 11 : 6049-6052. doi : 10.3748/wjg. v11.i38.6049 .

18. RAGHUWANSHI S., GUPTA R., VYAS M.M., SHARMA M. CT evaluation of acute pancreatitis and its prognostic correlation with CT severity index. $J$. Clin. Diagn. Res., 2016, 10 : 6-11. doi : 10.7860/JCDR/2016/19849.7934.

19. MORTELE K.J., WIESNER W., INTRIERE L., SHANKAR S., ZOU K.H., KALANTARI B.N., et al. A modified CT severity index for evaluating acute pancreatitis : improved correlation with patient outcome. Am. J. Roentgenol., 2004, 183 : 1261-1265. doi : 10.2214/ajr.183.5.1831261.

20. GRAVANTE G., GARCEA G., ONG S.L., METCALFE M.S., BERRY D.P., LLOYD D.M., et al. Prediction of Mortality in Acute Pancreatitis : A Systematic Review of the Published Evidence. Pancreatology., 2009, 9 : 601614. doi : 10.1159/000212097.

21. CHOI S.Y., KIM D., KANG J.H., PARK M.J., KIM Y.S., LIM S.H., et al. Nonalcoholic fatty liver disease as a risk factor of cardiovascular disease : relation of non-alcoholic fatty liver disease to carotid atherosclerosis. Korean J. Hepatol., 2008, $14: 1$ :77-88. doi : 10.3748/wjg.v19.i38.6453.

22. STEIN J.H., JOHNSON H.M. Carotid Intima-Media Thickness, Plaques, and Cardiovascular Disease Risk. Journal of the American College of Cardiology., 2010, 55 : 1608-1610. doi :10.1016/j.jacc.2009.11.073. 
23. TALEB S. Inflammation in atherosclerosis. Archives of Cardiovascular Disease, 2016, 109 : 708-715. doi : 10.1016/j.acvd.2016.04.002 .

24. CHO S.H., JEONG M.H., PARK I.H., CHOI J.S., YOON H.J., KIM K.H., et al. Endothelial dysfunciton, increased carotid artery intima-media thickness and pulse wave velocity and increased level of inflammatory markers are associated with variant angina. Journal of Cardiology, 2009, 54 : 183-191. doi : 10.1016/j.jjcc.2009.05.003.

25. MARTINEZ J, JOHNSON C, SÁNCHEZ-PAYÁ J, DE MADARIA E, ROBLES-DÍAZ G, PÉREZ-MATEO M., et al. Obesity is a definitive risk factor of severity and mortality in acute pancreatitis : an updated metaanalysis. Pancreatology., 2006, 6 : 206-209. doi : 10.1159/000092104.

26. PAPACHRISTOU G.I., PAPACHRISTOU D.J., AVULA H., SLIVKA A., WHITCOMB D.C. Obesity increases the severity of acute pancreatitis: Performance of APACHE-O score and correlation with the inflammatory response. Pancreatology., 2006, 6 : 279-285. doi : 10.1159/000092689.
27. PACIFICO L., CANTISANI V., ANANIA C., BONAIUTO E., MARTINO F., PASCONE E.R., et al. Serum uric acid and its association with metabolic syndrome and carotid atherosclerosis in obese children. Eur. J. Endocrinol., 2009, 160 : 45-52. doi : 10.1530/EJE-08-0618.

28. KARASEK D., VAVERKOVA H., FRYSAK Z., ORSAG J., NOVOTNY D., HALENKA M., SLAVIK L., et al. Association of serum adipocyte fatty acidbinding protein and apolipoprotein B /apolipoprotein A1 ratio with intima media thickness of common carotid artery in dyslipidemic patients. Biomed Pap. Med. Fac. Univ. Palacky Olomouc Chech Repub., 2019, 163 : 166-171. doi : $10.5507 / \mathrm{bp} .2018 .043$.

29. CALISKAN Z., DEMIRCIOGLU K., SAYAR S., KAHRAMAN R., CAKLILI O., OZCAN F.B., et al. Lipid profile, atherogenic indices, and their relationship with epicardial fat thickness and carotid intima-media thickness in celiac disease. North Clin. Istanb., 2019, 6 : 242-247. doi : 10.14744/ nci.2019.54936 